\title{
CLÁUSULAS ABUSIVAS EN LOS CONTRATOS DE TARJETA DE CRÉDITO $^{122}$
}

\author{
Amy Emperatriz Vílchez Villanueva \\ Labora en el Poder Judicial
}

\begin{abstract}
Resumen
El artículo desarrolla el tema referido a las clausulas abusivas en los contratos de tarjeta de crédito, para lo cual se procedió, como primer paso para comprender el tema y alcance del mismo, al estudio de la definición de tarjeta de crédito, su naturaleza jurídica, la función económica o el papel que desempeña en la sociedad. Se aborda de forma amplia el contrato de emisión de la tarjeta, instrumento jurídico que es donde se establecen o estipulan las cláusulas abusivas. Lo anterior, permite emitir un análisis crítico de las principales clausulas abusivas, aunque la ley no proporciona el concepto de éstas, teniendo que la Ley 515, Ley de Promoción y Ordenamiento del Uso de la Tarjeta de Crédito contempla una serie de clausulas que de incorporarse al contrato de tarjeta de crédito, éste resultaría nulo; no obstante la Ley no establece la forma en que se puedan impugnar ni el procedimiento que el usuario puede utilizar para tal fin. La Norma sobre la Promoción y Ordenamiento de la Tarjeta de Crédito solamente instaura el procedimiento relativo a la impugnación del estado de cuenta y no de las cláusulas abusivas.
\end{abstract}

La Ley de la Superintendencia de Bancos y Otras Instituciones Financieras no contiene de forma expresa la atribución de resolver el dilema mencionado, por lo que la Ley de Defensa de los Consumidores y su Reglamento puede ser una solución; sin embargo la Dirección de los Consumidores considera que esa es una función específica de la Superintendencia de Bancos. En ese sentido, el tarjetahabiente tiene como opción final utilizar la vía civil por medio de la acción de nulidad parcial del contrato.

Palabras clave: tarjeta de crédito/ tarjeta habiente/ emisor/ cláusulas abusivas

\section{Introducción}

El presente trabajo de investigación lleva a cabo un análisis general de las cláusulas abusivas impuestas por los emisores de tarjetas de crédito en los contratos de emisión, de conformidad con lo dispuesto en la Ley 515, de Promoción y Ordenamiento del Uso de Tarjetas de Crédito.

122 El presente artículo es el resultado del trabajo de investigación realizado para obtener el título de Máster en Derecho de Empresas con Especialización en Asesoría Jurídica; el cual además de ser evaluado por un Tribunal integrado por tres académicos; posteriormente, fue arbitrado por una Comisión a efectos de seleccionar a los participantes del I Encuentro de Investigación de Postgrado de la Universidad Centroamericana, 2009. 


\section{Reuista de Derecho}

La importancia de este estudio radica en la necesidad de que los usuarios de tarjetas de crédito o tarjetahabientes, conozcan cuáles son las cláusulas abusivas estipuladas en los contratos de emisión de tarjeta de crédito y los mecanismos de defensa que el ordenamiento jurídico vigente les concede ante tales abusos.

Para la realización de este trabajo, debido a que no existen estudios que específicamente aborden este tema, hice una recopilación doctrinal de libros y monografías, lo mismo que de modelos de contratos de emisión de tarjetas de crédito, enfocándome siempre en la legislación vigente en la materia, así como en la Ley de Defensa al Consumidor, y el Código Civil de la Republica de Nicaragua. De igual manera realicé una comparación con la legislación nacional y la legislación de otros países, logrando determinar que en nuestra legislación aún existen muchos vacíos en la materia de estudio, sin embargo, logré identificar cuáles son las principales cláusulas abusivas imperantes en estos contratos, a partir del análisis de dos contratos utilizados por instituciones bancarias diferentes.

En el desarrollo de mi trabajo, ofrezco, en primer término, una serie de conceptos o definiciones vinculados con la tarjeta de crédito como instrumento delegitimación, pasando por todos los elementos personales que integran el complejo sistema de la tarjeta de crédito, inclusive, la definición de lo que debe considerarse como cláusula abusiva, para orientar al lector a una mejor comprensión de los términos que incluye la ley.

\section{La tarjeta de crédito}

\section{Definición}

En la actualidad, la tarjeta de crédito o el denominado "dinero plástico" representa una etapa más en la evolución de los medios de pago, reemplazando de alguna manera el empleo del dinero en efectivo, cheques de banco u otro medio análogo, por un sistema de pago más rápido y seguro, en aras de la celeridad de las transacciones mercantiles y la tutela de los vendedores, compradores y el mercado mismo.

La tarjeta de crédito en términos generales puede definirse de la siguiente manera: 
Es un documento de tamaño reducido y de fácil manejo, que actúa como título de legitimación, intransferible, creado por una empresa especializada, entidad de crédito o establecimiento comercial, que previo contrato de emisión, permite a su titular obtener bienes o servicios sin necesidad de realizar su pago inmediato en dinero, limitándose éste, en el momento de la adquisición, a la firma de una factura o nota de cargo (boucher) que será presentada por el establecimiento suministrador al emisor de la tarjeta para abonar su importe y cargarlo posteriormente en la cuenta que mantiene con el titular ${ }^{123}$.

De conformidad con el artículo 1, inciso q) de la Norma sobre la Promoción y Ordenamiento del Uso de la Tarjeta de Crédito, la Tarjeta de Crédito se conceptualiza como "El instrumento o medio de legitimación, que puede ser magnético o de cualquier otra tecnología, cuya posesión acredita el derecho del tarjetahabiente o portador de tarjeta adicional, para disponer de la línea de crédito en cuenta corriente, derivada de una relación contractual previa entre el emisor y el tarjeta habiente”.

\section{Naturaleza jurídica}

Siendo que la tarjeta de crédito es un documento mercantil de carácter privado, la doctrina considera que la misma puede incluirse en la categoría de títulos valores en sentido amplio, porque cumplen una función similar, pero más exactamente su naturaleza jurídica corresponde a la de un título de crédito impropio o título de legitimación debido a que con su presentación identifica al titular y le permite el ejercicio de los derechos derivados del contrato; es decir, son representativas de un crédito, pero no con la autonomía y literalidad de los títulos valores ${ }^{124}$.

\section{Función económica}

La tarjeta de crédito no sólo se utiliza como instrumento de pago sino también como instrumento de garantía e instrumento de crédito. He ahí su triple función económica.

123 MONTERREY RÍOS Lydia. El Contrato Bancario de Tarjeta de Crédito en la Legislación Española y Nicaragüense y el Proyecto de Ley que lo regula Tercer Trimestre 2002 (Maestría en Derecho Privado). León, Universidad Nacional Autónoma de Nicaragua. UNAN-León, Facultad de Derecho, Página 26.

124 HERRERA ESPINOZA Jesús; Derecho Bancario Doctrina y Legislación, 2a Edición. Managua, UCA 2008, pagina 183 y 184 . 
1. Instrumento de pago: La tarjeta de crédito permite a su titular efectuar ciertas operaciones, bien con el propio emisor o bien con terceras personas, sin que tenga que utilizar dinero en efectivo, cheques $\mathrm{u}$ otros documentos mercantiles, como medio para la facilitación de los pagos.

2. Instrumento de garantía: Al momento de adquirir el bien o servicio en el establecimiento vendedor, el titular de la tarjeta de crédito al pagar se limita únicamente a exhibir la tarjeta, identificarse y firmar la nota o boucher correspondiente que contiene el monto acreditado, el que será abonado con posterioridad por el emisor a dicho establecimiento. Dicho de otra manera, la tarjeta de crédito por sí misma garantiza el pago del bien o servicio.

3. Instrumento de crédito: Se refiere a que los gastos efectuados por el titular de la tarjeta se reembolsarán en una fecha posterior a la de la utilización de la tarjeta de crédito $^{125}$.

Finalmente la tarjeta de crédito cubre, en casos especiales, una función económica adicional, la de ser un instrumento que permite a su titular obtener dinero por mecanismos electrónicos o cajeros automáticos ${ }^{126}$.

\section{Sistema de la tarjeta de crédito}

\section{Elementos personales}

\subsection{Emisor}

Es la persona o entidad que expide la tarjeta de crédito y la pone a disposición de sus clientes, previa suscripción del contrato de emisión de tarjeta de crédito, con el objetivo de utilizarla como medio de pago en la adquisición de bienes o servicios, asumiendo el emisor, en todos los casos, el compromiso de hacer efectivo el importe de las facturas cubiertas por su garantía.

Desde el punto de vista jurídico, el emisor puede ser:

a) Un empresario que emite la tarjeta para que sea utilizada en sus propios establecimientos.

125 GÓMEZ PORRÚA Juan Manuel, "La Tarjeta de Crédito" en Derecho Mercantil, Vol. II, 4a edición, dirigido por Jiménez Sánchez, Guillermo, Editorial Ariel S.A., Barcelona 1990 y 1997, página 191.

126 GÓMEZ PORRÚA Juan Manuel, "La Tarjeta de Crédito" en Derecho Mercantil, Vol. II, 4a edición, dirigido por Jiménez Sánchez, Guillermo, Editorial Ariel S.A., Barcelona 1990 y 1997, página 192. 
b) Una entidad queemitela tarjeta para su utilización en establecimientos distintos con los que previamente ha suscrito un contrato.

c) Una entidad crediticia que emite la tarjeta para su utilización en los establecimientos distintos con los que previamente ha suscrito un contrato $^{127}$.

En todo caso el emisor ocupa una posición predominante dentro del sistema de la tarjeta de crédito debido a que es éste quien redacta las condiciones generales por las que se regirán las relaciones jurídicas que se derivan de la utilización de la tarjeta de crédito, tanto para el titular como para el establecimiento asociado, a las que éstos se adhieren sin posibilidad de introducir modificación alguna.

\subsection{Entidad de franquicia}

Figura que asume un papel fundamental en la emisión de la tarjeta de crédito, ésta es la propietaria o titular de la marca de la tarjeta de crédito y la que a su vez autoriza al emisor para poner en circulación la referida tarjeta con carácter exclusivo o compartido, en un determinado país o zona. Es posible mencionar algunas de las marcas más famosas de tarjetas de crédito, tales como MasterCard, Visa, American Express, Dinner's Club, entre otras.

\subsection{Contratante, titular, tarjetahabiente y beneficiarios}

El titular es la persona autorizada por el emisor para utilizar la tarjeta de crédito, bien ella misma o un beneficiario, en virtud de un contrato suscrito con el emisor. Sin embargo, en muchas ocasiones el titular no siempre es la parte contratante. En ocasiones se produce una confusión entre ambas figuras (titular y contratante); cuando esto sucede, para todos los efectos es la misma persona quien asume exclusivamente tanto las obligaciones como los beneficios derivados de la tarjeta de crédito. Por el contrario, cuando no se produce dicha confusión o no es absoluta es preciso distinguirse dos supuestos:

- Cuando el titular es a su vez contratante, pero designa a otras personas para que puedan utilizar la tarjeta, es preciso distinguir entre titular básico o contratante y titulares autorizados o beneficiarios. Esto

127 MOJICA Luis, O’MIER Francis, TÉLLEZ Orlandina. La Tarjeta de Crédito y su Regulación en Nicaragua, Monografía (Licenciados en Derecho), León, Nicaragua, Universidad Nacional Autónoma de Nicaragua, UNAN-León página 46 y 47. 


\section{Revista de Derecho}

sucede generalmente cuando se está en presencia de las denominadas tarjetas familiares. La celebración de un único contrato da lugar a la emisión de varias tarjetas de crédito a favor del contratante y sus beneficiarios, y donde las obligaciones que se deriven del contrato mismo son asumidas exclusivamente por el titular básico o contratante.

- Cuando el contratante no es titular, sin embargo asume las obligaciones derivadas del contrato y designa en el mismo a otra $\mathrm{u}$ otras personas como beneficiarias del mismo. Este es el caso de las tarjetas de empresas solicitadas por estas para sus directivos o empleados $^{128}$.

Conviene comentar que la Ley 515 Ley de Promoción y Ordenamiento del Uso de la Tarjeta de Crédito, hace referencia a esta figura usando el término de "usuario de la tarjeta de crédito", de manera que dicha norma utiliza indistintamente los términos de contratante y tarjetahabiente.

La Norma sobre la Promoción y Ordenamiento del Uso de la Tarjeta de Crédito (Resolución No. CD-SIBOIF-443-1-SEP26-2006) desarrolla en su artículo 1, inciso p), el concepto de tarjeta habiente de la siguiente manera: "Persona natural o jurídica que, previo contrato con el emisor, es habilitada para el uso de una línea de crédito revolvente".

\subsection{Avalista o fiadores}

Esta es una figura estrechamente relacionada con el titular, cuya presencia puede ser exigida por el emisor para reforzar la solvencia del titular. Este garantizará las obligaciones frente al emisor y responderá solidariamente con el titular de las deudas ocasionadas por la tenencia y uso de la tarjeta de crédito, autorizándose normalmente al emisor en las condiciones generales del contrato a dirigirse indistintamente contra uno u otro, o contra ambos simultáneamente.

Cabe destacar que siendo que la naturaleza de la tarjeta de crédito la de un título de crédito impropio o de legitimación y no la de un título valor, en nuestro ordenamiento jurídico la figura que usualmente se exige en la emisión de la tarjeta de crédito es la de los fiadores (no la de avalista), mediante la celebración de un contrato de fianza (contrato accesorio). En este tipo de contratos se suele pactar que la fianza sea

128 Artículo 9 de la Ley 515, "Ley de Promoción y Ordenamiento del Uso de la Tarjeta de Crédito". 


\section{Revista de ODerecho}

solidaria por lo que no opera el beneficio de excusión. Sin embargo, el fiador solidario en este caso, queda exento de responsabilidad alguna de pagar cualquier suma proveniente de créditos autorizados por el emisor al tarjetahabiente, en exceso al límite original de crédito pactado, salvo cualquier ampliación al mismo en el que el fiador diere su autorización expresa de forma escrita ${ }^{129}$.

\subsection{Empresa o establecimiento afiliado}

El establecimiento asociado no es sólo el que facilita al titular los bienes o servicios que éste necesita, sino el que admite la tarjeta de crédito como medio de pago, cargando posteriormente su importe al emisor y soportando frente a éste, el descuento correspondiente a la comisión concertada.

Vale la pena señalar que la posición jurídica del establecimiento dentro del sistema de la tarjeta de crédito difiere según que sea el propio emisor o un establecimiento distinto e independiente con el que previamente el emisor ha concertado la admisión de la tarjeta como medio de pago; produciéndose una situación intermedia cuando la tarjeta de crédito es emitida por una asociación de empresarios para su utilización en sus respectivos establecimientos.

\section{Relaciones contractuales en el sistema de la tarjeta de crédito}

El denominado sistema de la tarjeta de crédito presupone a partir de la emisión de la tarjeta de crédito, la existencia de un complejo contractual, por la diversidad de relaciones jurídicas, con autonomía y regulación propia pero que se complementan en un circuito, fuera del cual resultarían ineficaces ${ }^{130}$.

Es así que pueden distinguirse dos relaciones jurídicas básicas distintas: entre el emisor y titular o tarjetahabiente, y por otra parte, entre el emisor y el establecimiento asociado; sumándose a las anteriores otra relación contractual que nace como consecuencia de la utilización de la tarjeta: la relación entre el titular o tarjeta habiente y el establecimiento asociado.

129 BENDAÑA GUERRERO Guy, "Tarjeta de Crédito", Estudio de los Contratos. $1^{a}$ Edición, Managua, Septiembre 2001, página 598.

130 Artículo 1 de la Ley 515. 


\section{Revisla de Derecho}

Ahora bien, puede darse el caso en que el emisor no es propietario de la marca de la tarjeta de crédito, por lo que se hace necesario incluir dentro del Sistema otro tipo de relación, la que se establece entre el emisor (Banco) y la entidad de franquicia.

\subsection{Relación entre emisor (Banco) y tarjetahabiente}

De conformidad con la Ley 515 Ley de Promoción y Ordenamiento del Uso de la Tarjeta de Crédito, la relación que se produce entre el emisor y el tarjetahabiente es la de un contrato de apertura de crédito en cuenta corrientey emisión y uso de tarjeta decrédito, cuyas operaciones derivadas del mismo deben ser previamente autorizadas por la Superintendencia de Bancos y Otras Instituciones Financieras ${ }^{131}$, como órgano regulador.

El contrato en mención se caracteriza por ser consensual, típico, formal, de adhesión, en serie, sinalagmático y de ejecución continuada, mediante el cual el emisor pone a disposición del tarjetahabiente un monto de crédito y se compromete a pagar por cuenta del titular, las facturas de bienes y servicios que éste haya adquirido y firmado en los establecimientos. Por otro lado, el tarjetahabiente, se obliga a restituir el dinero objeto del negocio y la satisfacción de los intereses y comisiones pactadas, en los plazos y términos convenidos ${ }^{132}$.

Es de observar que la Ley 515 señala claramente que la relación entre el emisor de la tarjeta de crédito y el usuario se rige bajo el principio de la buena fe en los negocios ${ }^{133}$, marcando así la diferencia con el resto de contratos típicos en nuestro ordenamiento jurídico.

\subsection{Relación entre emisor (Banco) y establecimiento asociado}

La relación entre el emisor y el establecimiento asociado nace a partir de la celebración de un contrato de afiliación que se perfecciona mediante la firma de un formulario en el que ya vienen impresas las cláusulas y en virtud del cual el establecimiento se adhiere al sistema de tarjeta de crédito, se convierte en colaborador del emisor y compromete a admitir la tarjeta de crédito como medio de pago de los bienes o servicios que

131 HERRERA ESPINOZA, Jesús Jusseth; Derecho Bancario; Doctrina y Legislación, 2da Edición, Managua: UCA 2008, página 190.

132 Artículo 4, párrafo 3ro. de la Ley 515.

133 BARBIERI Pablo C., "Contratos de Financiación: Tarjeta de Crédito" en Contratos de Empresa; Edición Universidad, España 1998, página 227. 


\section{Revista de ODerecho}

facilita al titular, y a emitir una factura que firma el titular, con la garantía de su pago por el emisor, que cobra o descuenta una comisión del importe de las mismas.

Por lo anterior, este tipo de contrato puede describirse como un contrato de adhesión, consensual (se perfecciona cuando el emisor comunique al comerciante la aceptación de su oferta de afiliación), en serie, bilateral o sinalagmático y de ejecución continuada. Es además un contrato de carácter atípico que contiene una estipulación a favor de un tercero (tarjetahabiente), con obligaciones recíprocas para las partes contratantes ${ }^{134}$.

\subsection{Relación entre tarjetahabiente y establecimiento asociado}

Las relaciones entre el titular o beneficiario de la tarjeta de crédito y el establecimiento asociado son las derivadas directamente de los bienes o servicios que el titular adquiere o contrata beneficios a favor del tarjetahabiente que el emisor haya estipulado en el contrato de establecimiento (compraventa, arrendamiento, transporte, etc.), y, por otra parte, las condiciones de afiliación.

Las relaciones que surgen entre el titular o beneficiario y el establecimiento, a consecuencia de los bienes adquiridos o los servicios prestados, sólo obligan a ambas partes, por lo que eximen al emisor de responsabilidad en las controversias que puedan derivarse. Sin embargo, una vez firmado el boucher por el titular, y presentado al emisor por el establecimiento, el emisor está obligado a realizar el pago por cuenta del titular, siempre que el establecimiento haya verificado el cumplimiento de los requisitos establecidos por el emisor (identificación, firma, límite de crédito, fecha de expiración).

Finalmente, como consecuencia del contrato existente entre el emisor y el establecimiento, el titular tiene derecho a exigir de éste último la aceptación de la tarjeta de crédito como medio de facilitación del pago.

\subsection{Relación entre emisor y entidad de franquicia}

La relación entre el emisor y la propietaria de la marca es un "contrato de franquicia o licencia de utilización de la marca en la emisión de la

134 GÓMEZ PORRÚA Juan Manuel, "La Tarjeta de Crédito" en Derecho Mercantil, Vol. II, 4a edición, dirigido por Jiménez Sánchez, Guillermo, Editorial Ariel S.A., Barcelona 1990 y 1997, página 196. 


\section{Revisla de Derecho}

tarjeta de crédito" ${ }^{135}$, mediante el cual la entidad de franquicia autoriza al emisor a poner en circulación la tarjeta de crédito con el logotipo de su marca, en determinado país o zona geográfica, con carácter exclusivo o compartido.

\section{Contrato de emisión de la tarjeta de crédito}

\section{Noción del contrato de emisión de la tarjeta de crédito}

El contrato de emisión de tarjeta de crédito es aquel por el cual una empresa bancaria o una persona jurídica autorizada (por ejemplo una sociedad financiera), concede una apertura de crédito en cuenta corriente, con una cuantía determinada, a favor de su cliente para que utilizando la tarjeta de crédito como medio de pago, pueda adquirir bienes o pagar servicios en los establecimientos afiliados o adheridos al sistema de tarjeta de crédito, cuyos consumos serán cancelados al contado y a cierto plazo convenido.

En la práctica, para llegar al contrato, se inicia con la firma de una solicitud de tarjeta por parte del cliente que necesita la ulterior conformidad del emisor. Sin embargo, actualmente muchas empresas emisoras usualmente otorgan tarjetas aprobadas previamente, sin necesidad de la solicitud, bastando que el titular de la tarjeta acepte la tarjeta de crédito, la firme y avise al titular que la ha recibido. Mientras no exista esta conformidad no habrá contrato y, en consecuencia, no podrá hablarse de derechos ni obligaciones de las partes.

La característica principal de este contrato es que obedece a los denominados "contratos tipo" o "de adhesión", que se suelen realizar a través de "condiciones generales de la contratación", es decir, que las cláusulas del contrato son impuestas por una de las partes, llámese emisor de la tarjeta de crédito, y que no cabe posibilidad de negociación por parte del titular de dicha tarjeta.

135 MONTERREY RÍOS Lydia. El Contrato Bancario de Tarjeta de Crédito en la Legislación Española y Nicaragüense y el Proyecto de Ley que lo regula Tercer Trimestre 2002 (Maestría en Derecho Privado). León, Universidad Nacional Autónoma de Nicaragua. UNAN-León, Facultad de Derecho, Página 36. 


\section{Revista de ODerecho}

\section{Características del contrato}

El contrato de emisión de la tarjeta de crédito se caracteriza por ser un contrato nominado, formal, principal, de adhesión, en serie, oneroso, bilateral, de ejecución continuada, consensual e intuito personae ${ }^{136}$. A continuación, una breve explicación sobre las características de este contrato:

- Nominado o típico: Se encuentra previsto y regulado en la Ley 515, "Ley de Promoción y Ordenamiento del Uso de la Tarjeta de Crédito".

- Formal: Debe estar redactado de forma escrita.

- Principal: No depende de otro contrato, tiene vida propia.

- De adhesión: Sus cláusulas son fijadas unilateralmente por el emisor, limitándose el titular a aceptarlas o simplemente rechazarlas, rehusando la contratación.

- En serie: Por el fenómeno de la contratación en masa, en el que las condiciones generales establecidas por el emisor son idénticas para todos los titulares, pudiendo variar el crédito concedido, el importe máximo de la cantidad de la que puede disponer diariamente el titular y el sistema de pago.

- Oneroso: Las ventajas que se asegura el titular o tarjetahabiente son a cambio de una contraprestación en dinero.

- Bilateral o sinalagmático: Genera derechos y obligaciones tanto para el emisor como para el titular.

- De ejecución continuada: Las prestaciones que realizan las partes no se agotan en el momento de la celebración del contrato sino que perduran con posterioridad al mismo.

- Consensual: Se perfecciona al momento en que se produce la aceptación por parte del emisor, de la solicitud presentada por el futuro titular.

- Intuitu Personae: Está referida a una persona determinada de acuerdo a su solvencia moral y económica.

\section{Naturaleza jurídica del contrato}

La tarjeta de crédito se emite con razón de la celebración de un “contrato de apertura en cuenta corriente y emisión y uso de la tarjeta de crédito"137, suscrito entre el emisor de la tarjeta de crédito y el usuario (Titular o Tarjeta habiente).

136 Artículo 2 de la Ley 515, "Ley de Promoción y Ordenamiento del Uso de la Tarjeta de Crédito". 137 Articulo 16 de la Norma sobre la Promoción y Ordenamiento del Uso de la Tarjeta de Crédito. 
En términos generales, el contrato de apertura en cuenta corriente es aquél por el cual la entidad emisora (banco) asegura al cliente que ha de disponer de un crédito (dinero), el que será utilizable mediante un sistema de compras o de adquisición de servicios en determinados comercios, en las condiciones convenidas y en la forma que se reglamenta en el contrato normativo.

\section{Requisitos formales}

De conformidad con el artículo 10 de la Ley 515, el contrato de emisión de la tarjeta de crédito deberá reunir las siguientes condiciones:

1. Deberá ser redactado en ejemplares de un mismo tenor para el emisor, para el eventual fiador personal del titular, en su caso, y para el usuario autorizado que tenga responsabilidades frente al emisor. El emisor deberá entregar tantas copias del contrato como partes intervengan en el mismo.

2. El contrato deberá redactarse claramente y con tipografía fácilmente legible a simple vista.

3. Las cláusulas que generen responsabilidad para el usuario de la tarjeta de crédito deben estar redactadas mediante el empleo de caracteres destacados o subrayado.

De manera complementaria, la Norma sobre la promoción y ordenamiento del uso de la tarjeta de crédito establece de igual forma una serie de condiciones que se enumeran a continuación:

1. El tamaño de la letra de los contratos, en ningún caso podrá ser menor al tamaño y tipo de letra utilizados para las publicaciones en el Diario Oficial, La Gaceta.

2. Las cláusulas que generen responsabilidad para el tarjetahabiente y fiador solidario de la tarjeta de crédito deben estar redactadas mediante el empleo de caracteres destacados en negrilla o subrayados.

3. Los contratos deberán ser firmados por el representante legal del emisor o persona previamente autorizada para tal fin, así como por el tarjetahabiente y por el eventual fiador personal del titular, en su caso. La firma del representante legal del emisor o de la persona previamente autorizada para tal fin podrá ser preimpresa en el proceso de elaboración de la forma utilizada para la emisión del contrato, o impresa electrónicamente en el proceso de elaboración 
del mismo. Para ambos casos, el emisor deberá implementar las medidas de seguridad y controles internos necesarios para evitar posibles falsificaciones o alteraciones a dichos contratos.

Sin embargo, adicionalmente, el artículo 5 de la Norma sobre la promoción y ordenamiento del uso de la tarjeta de crédito señala que los modelos de contratos deberán contener:

1. Nombre del contrato: Contrato de apertura de crédito en cuenta corriente y emisión y uso de tarjeta de crédito.

2. Contratantes: Relación de la entidad emisora como sociedad anónima domiciliada en Nicaragua, indicando el número de la escritura, notario autorizante e inscripción registral, carácter con que actúa (emisor o coemisor) y quien la representa; de igual manera relacionar estos mismos requisitos tratándose de persona jurídica, usuaria del crédito y quien la representa; en el caso que el tarjeta habiente sea una persona natural, nombre conforme cédula de identidad, número de cédula y dirección del domicilio.

3. Monto inicial de la línea de crédito expresada en cifras y tipo de moneda contratada.

4. Plazo del contrato y la condición de prórroga automática del mismo, en su caso.

5. Tasa de interés corriente anual y tasa moratoria anual.

6. Tipo de tasa de interés (fija o variable). En el caso de tasa de interés variable, indicar la tasa de referencia o índice más los puntos porcentuales en que puede ser incrementada.

7. Plazo o período para revisión de tasa de interés (fija o variable).

8. Definición de las comisiones, honorarios y cargos conexos al uso de la tarjeta de crédito.

9. Definición del monto y plazos sobre el cual se aplicarán los intereses (corrientes y moratorios).

10. Definición de lo que comprende el pago de contado.

11. Definición y condiciones del período de gracia, según el caso.

12. Definición de lo que comprende el pago mínimo.

13. Forma y medios de pago permitidos.

14. Procedimientos y responsabilidades de las partes en caso de extravío, robo, deterioro o sustracción de la tarjeta de crédito.

15. Casos en que procede la suspensión del uso de la tarjeta de crédito o la resolución del contrato respectivo por voluntad unilateral del emisor o del tarjeta habiente. 
16. Periodicidad de entrega del estado de cuenta.

17. Procedimiento para impugnación de cargos.

18. Monto máximo garantizado por el fiador solidario, según el caso.

19. Información sobre garantías diferentes a la fianza solidaria, según el caso.

20. Derechos y obligaciones del tarjeta habiente y fiador solidario.

21. Tabla de costos.

22. Descripción de los casos en que el adeudo total puede ser considerado como vencido y requerido el pago total al tarjeta habiente.

23. Otros requisitos que establezca el Superintendente.

5. Obligaciones generadas a partir del contrato de emisión de la tarjeta de crédito

5.1. Del emisor

- Entregar copia del contrato que firman los usuarios.

- Poner a disposición del cliente, en la forma y tiempo acordados, cantidades de dinero que éste último le exija dentro de los términos convenidos.

- Enviar a sus tarjeta habientes el estado de cuenta mensual a la dirección indicada, a más tardar siete días hábiles después de la fecha de corte, cumpliendo con la información requerida por la Ley ${ }^{138}$. Sumado a esto, considero que debería ser también obligatorio, para las entidades emisoras de tarjeta de crédito, consignar en los resúmenes de estado de cuenta, entre otras cosas, la fecha a partir de la cual se calcularían los intereses y el procedimiento de impugnación de las liquidaciones.

- Informar al tarjeta habiente que dispone de treinta días calendario, a partir de la fecha de corte, para impugnar el estado de cuenta. Recibida la impugnación, el emisor deberá acusar recibo y dispondrá de un plazo no mayor de seis meses para dar respuesta a la misma ${ }^{139}$.

- Poner a disposición del usuario de la tarjeta de crédito, un número telefónico con servicio las veinticuatro horas del día, con el fin de recibir informe sobre robo, extravío o pérdida de la tarjeta de crédito, todo con la intención de proceder al "bloqueo" de ésta, de forma inmediata ${ }^{140}$.

- En caso de que se efectúe alguna modificación (agregar nuevas cláusulas o reformar las existentes) en el contrato de emisión

138 Articulo 17 de la Norma sobre la Promoción y Ordenamiento del Uso de la Tarjeta de Crédito.

139 Artículo 12 de la Ley 515.

140 Artículo 7 y 8 de Norma sobre la Promoción y Ordenamiento del Uso de la Tarjeta de Crédito. 
de la tarjeta de crédito, una vez aprobada previamente por el Superintendente, el emisor deberá publicarlo por cualquier medio de comunicación social de circulación nacional. Así mismo, deberá notificar al tarjetahabiente en el estado de cuenta el medio de comunicación social escrito y fecha de publicación de las modificaciones del contrato, previniéndolo del derecho de rechazar dichas modificaciones, por escrito $u$ otro medio verificable, en un plazo de 30 días ${ }^{141}$.

- Notificar al tarjeta habiente cuando exista incremento de la tasa de interés fija, con un plazo de antelación no menor de treinta días, previniéndole que puede rechazarlo por escrito en un plazo de treinta días calendario contados a partir de la fecha límite de pago. Lo mismo sucede cuando se incrementa de la tasa variable, excepto que en ese caso no se requiere de la aceptación del tarjetahabiente ${ }^{142}$.

- Notificar al fiador solidario el estado de mora en que ha incurrido el usuario de la tarjeta de crédito (deudor principal), en un plazo no mayor de treinta días posteriores de ocurrido tal hecho ${ }^{143}$.

- En caso de que el fiador solidario haya cancelado la obligación del tarjeta habiente, el emisor deberá entregarle una certificación de cancelación de la obligación, así como copia certificada de la documentación necesaria para que pueda ejercer su derecho de cobro al tarjetahabiente ${ }^{144}$.

La Ley 515 se ha limitado a incorporar únicamente las obligaciones que surgen a partir de la celebración del contrato de emisión de la tarjeta de crédito, y ha dejado fuera aquellas obligaciones previas y posteriores al contrato, tales como:

- Deber de brindar al usuario una información clara, adecuada, inteligible y completa de los productos y servicios ofertados por el emisor y las contraprestaciones y gastos en los que puede incurrir el tarjetahabiente ${ }^{145}$. En ese sentido, en el caso específico de las tarjetas de crédito, las instituciones bancarias que fungen como emisores de dicho instrumento, tienen el deber de claridad, concreción y sencillez en la redacción del contenido del contrato mediante el cual se emite la tarjeta de crédito.

141 Artículo 10 Norma sobre la Promoción y Ordenamiento del Uso de la Tarjeta de Crédito.

142 Artículo 9 de la Ley 515 y 24 de la Norma sobre la Promoción y Ordenamiento del Uso de la Tarjeta de Crédito.

143 Artículo 25 de Norma sobre la Promoción y Ordenamiento del Uso de la Tarjeta de Crédito.

144 Artículo 20 de la Declaración Universal de Derechos de los Usuarios de los Servicios Bancarios y Financieros. Salamanca, España, 29 y 30 de Septiembre 2005.

145 Artículo 3, inciso b) de la Ley de Defensa de los Consumidores. 


\section{Revista de Derecho}

Es de observarse que en la realidad práctica, generalmente los contratos de adhesión suelen ser prolíficos en terminología legalista, y complejos de entender para el usuario o consumidor, corriendo el riesgo de ser engañados, dañados y abusados por el emisor, firmando el contrato casi a ciegas debido a la falta de comprensión absoluta del mismo.

En otro orden, la letra pequeña constituye prácticamente una de las características definitorias de los contratos de adhesión, debido a que se utilizan mecanismos que, al margen de la complejidad de los términos, dificultan su lectura por los usuarios.

- Deber de educar al usuario para el consumo ${ }^{146}$, entendiéndose que es obligación del emisor, instruir al tarjetahabiente no sólo para el uso de dicha tarjeta sino también para la comprensión de la metodología de cálculo que utiliza el emisor para el cobro de intereses y comisiones que se verán materializadas en el estado de cuenta correspondiente.

\subsection{Del tarjetahabiente}

- Restituir la cantidad de dinero objeto del negocio:

a) El pago total del saldo adeudado a la fecha de corte, expresado en la moneda pactada.

b) El pago mínimo, es decir, aquel que corresponde al pago del ciclo en la moneda pactada, que cubra una amortización no menor de $2.5 \%$ del saldo principal, más los intereses corrientes y moratorios ${ }^{147}$.

- La satisfacción de los intereses:

a) Interés corriente

b) Interés moratorio

Ambos intereses se calcularán de acuerdo con el método establecido en el artículo 12 de la Norma sobre la promoción y ordenamiento del uso de la tarjeta de crédito.

Es de aclarar que de conformidad con el artículo 50 de la Ley 561, los bancos podrán pactar libremente con sus clientes las tasas de interés; sin embargo, la ley protege a los usuarios al tipificar el delito de usura cuando se cobre un interés mayor al previamente establecido en el contrato, aún cuando dicho interés o recargo se encubra o disimule de cualquier

146 Artículo 14 de Norma sobre la Promoción y Ordenamiento del Uso de la Tarjeta de Crédito.

147 Artículo 13 de la Ley 515. 
Revista de Oerecho.

manera, o se le dé otras denominaciones, tales como pago vencido, cargo por servicios, o cualesquiera otros términos o conceptos ${ }^{148}$.

- Pago de las comisiones pactadas:

a) Deberá estar previamente establecido en el contrato de adhesión, en su defecto, aceptado expresamente por el usuario de la tarjeta de crédito para que le pueda ser cobrado en su estado de cuenta correspondiente ${ }^{149}$.

b) Para todos los efectos los emisores podrán cobrar en concepto de comisiones, honorarios y otros cargos los siguientes: Comisión por retiros de efectivo, honorarios por gestión de cobro extrajudicial, cargo por reposición de tarjeta, cargo por membresía, cargo por sobregiro, cargo por mantenimiento de valor y otros cargos previamente autorizados por el Superintendente ${ }^{150}$.

\section{Derechos establecidos a favor de los contratantes}

A la luz de la Ley 515 y la Norma sobre la Promoción y Ordenamiento del Uso de la Tarjeta de Crédito se establecen los siguientes derechos a favor de los principales protagonistas en esta relación contractual: Del emisor y el tarjetahabiente.

\subsection{Del emisor}

- Derecho a que el tarjeta habiente le restituya la cantidad de dinero objeto del negocio, sea en concepto de pago mínimo, o bien, el pago total del saldo adeudado a la fecha de corte, expresado en la moneda pactada ${ }^{151}$.

- Derecho a que los intereses corrientes y moratorios le sean satisfechos de acuerdo a lo convenido en el contrato de emisión de la tarjeta de crédito.

- Derecho al pago de las comisiones previamente establecidas en el contrato de adhesión y aceptadas expresamente por el usuario de la tarjeta de crédito ${ }^{152}$.

- En caso de que el tarjetahabiente haya impugnado el estado de cuenta, mientras dure el proceso de impugnación el emisor podrá exigir el pago mínimo de los rubros no impugnados ${ }^{153}$.

148 Artículo 7 de la Ley 515.

149 Artículo 13 de Norma sobre la Promoción y Ordenamiento del Uso de la Tarjeta de Crédito.

150 Artículo 14 de Norma sobre la Promoción y Ordenamiento del Uso de la Tarjeta de Crédito.

151 Artículo 7 de la Ley 515.

152 Artículo 19 de Norma sobre la Promoción y Ordenamiento del Uso de la Tarjeta de Crédito.

153 Artículo 16 de la Norma sobre la Promoción y Ordenamiento del Uso de la Tarjeta de Crédito. 
Revista de Derecho

\subsection{Del tarjetahabiente}

- Disponer de cantidades de dinero, en la forma y tiempo convenido en el contrato de emisión de la tarjeta de crédito. En este caso, el emisor de la tarjeta no puede cancelar sin motivo y antes de su vencimiento una tarjeta de crédito otorgada.

- Recibir el estado de cuenta mensual a la dirección indicada, a más tardar siete días hábiles después de la fecha de corte. Se prohíbe cualquier tipo de cobro adicional al precio de venta ofrecido por los proveedores de bienes y servicios ${ }^{154}$. Apuntando un poco sobre este derecho, considero que no basta con cumplir término establecido para su recibo y con la información exigida por la ley, sino que además; que la misma sea de fácil comprensión para el usuario.

- Derecho a impugnar, sin costo alguno, el estado de cuenta utilizando los formularios preestablecidos por el emisor, en el término de treinta días calendario, a partir de la fecha de corte ${ }^{155}$. Durante el procedimiento de impugnación, el tarjetahabiente podrá utilizar la tarjeta de crédito sin ningún impedimento, dentro del límite autorizado, entendiéndose que el monto impugnado formará parte de dicho límite mientras no sea resuelta la impugnación ${ }^{156}$.

- En caso de que la impugnación se resuelva a favor del tarjeta habiente, éste tiene derecho a que se le revierta el cargo impugnado, los intereses y cualquier otro cargo ${ }^{157}$.

- Disponer de un número telefónico con servicio las veinticuatro horas del día para informar al emisor, en caso de robo, extravío o pérdida de la tarjeta de crédito, con el objetivo de bloquearla de forma inmediata ${ }^{158}$.

- Cuando se haya efectuado alguna modificación en el contrato de emisión de la tarjeta de crédito, el tarjetahabiente tiene derecho a que se le notifique en el estado de cuenta el medio de comunicación social escrito y fecha de publicación de tal modificación del contrato, con el objetivo de facultarlo para rechazarlas, por escrito u otro medio verificable, en un plazo de 30 días ${ }^{159}$.

- Derecho a ser notificado cuando exista incremento de la tasa de interés fija, con un plazo de antelación no menor de treinta días,

154 Artículo 17 de la Norma sobre la Promoción y Ordenamiento del Uso de la Tarjeta de Crédito.

155 Artículo 19 de la Norma sobre la Promoción y Ordenamiento del Uso de la Tarjeta de Crédito.

156 Artículo 19 de la Norma sobre la Promoción y Ordenamiento del Uso de la Tarjeta de Crédito.

157 Artículo 12 de la Ley 515.

158 Artículo 7 y 8 de Norma sobre la Promoción y Ordenamiento del Uso de la Tarjeta de Crédito.

159 Artículo 10 Norma sobre la Promoción y Ordenamiento del Uso de la Tarjeta de Crédito. 


\section{Revista de ODerecho}

previniéndolo que puede rechazarlo por escrito en un plazo de treinta días calendario contados a partir de la fecha límite de pago ${ }^{160}$.

Adicionalmente, existen otros derechos que considero que los usuarios o tarjeta habientes deben tener, y que a su vez no se encuentran contenidos en la Ley 515, pero que por su importancia deben ser garantizados por la ley, tales como:

- Derecho a suscribir un contrato de fácil comprensión y legible, que no contenga cláusulas abusivas o que restrinjan sus derechos.

- Derecho a recibir copia de toda la documentación que suscriba el usuario con motivo del contrato de tarjeta de crédito.

- Derecho a la información adecuada antes, durante y después de la celebración del contrato de emisión de tarjeta de crédito sobre las condiciones del contrato, los intereses y las comisiones. Además el usuario debe ser informado sobre las ventajas y posibles inconvenientes que puede generar el uso de la tarjeta de crédito y sobre el funcionamiento en general, recibiendo las recomendaciones necesarias para evitar y prevenir cualquier perjuicio.

- Derecho a la educación para el consumo, establecido en el artículo 11, inciso b) de la Ley de Defensa del Consumidor.

- Derecho a la protección de datos personales que las entidades financieras obtengan para la prestación de sus servicios ${ }^{161}$. En Nicaragua, no se protegen adecuadamente dichos datos enfocándose, únicamente en proteger el interés público, otorgándoles a las entidades emisoras de tarjetas de crédito la facultad de darse a conocer entre ellas el historial de pago del usuario de la tarjeta de crédito con conocimiento previo del mismo, sin embargo en la práctica no siempre se cuenta con dicha aprobación.

\section{Análisis crítico de las principales cláusulas abusivas en el contrato de emisión de la tarjeta de crédito}

Antes de realizar el estudio sobre las cláusulas abusivas en el contrato de emisión de la tarjeta de crédito, se hace necesario recordar que dicho contrato se configura como un contrato de adhesión, es decir, aquél cuyas cláusulas o condiciones generales se establecen o predisponen por el emisor, sin que el contratante o tarjetahabiente pueda influir, discutir

160 Artículo 28 de la Declaración Universal de Derechos de los Usuarios de los Servicios Bancarios y Financieros. Salamanca, España, 29 y 30 de Septiembre 2005.

161 NAVAS MENDOZA Azucena, Curso Básico de Derecho Mercantil, Tomo II, León, Nicaragua, Editorial Universitaria, UNAN, León, 2004, página 182. 


\section{Revista de Derecho}

o modificar sustancialmente su contenido al momento de su celebración. Generalmente siempre tiene la forma de una solicitud, en formularios preimpresos con cláusulas generales, impuestas por la empresa emisora y que deberá ser firmada por el cliente.

He aquí una visión clara de que la tarjeta se emite mediante un contrato, pero en su materialización es considerada una solicitud hecha para todos los fines por el cliente al banco emisor, pero cuyo contenido (cláusulas) son establecidas unilateralmente por éste, limitándose únicamente aquél a "aceptar" dicha solicitud.

Todo lo anterior nos obliga a estudiar un poco sobre la problemática que en la práctica contractual genera la existencia de las condiciones generales en el contrato de consumo, o en los contratos con consumidores, tema que ha sido largamente discutido por la doctrina internacional.

Es así que desde el punto de vista doctrinario se ha considerado que los contratos celebrados sobre la base de condiciones generales suscitan fundamentalmente tres tipos de problemas:

1. El adherente desconoce las cláusulas que van a formar parte del contrato.

2. Se favorece la inserción de cláusulas abusivas.

3. Necesidad de vencer la inercia del adherente a través de medidas preventivas activas por ciertas instituciones $u$ organizaciones (Asociaciones de defensa de los consumidores) ${ }^{162}$.

A la vista de esto, un control eficaz debería actuar en tres direcciones:

1. Mediante la consagración destinada a un acuerdo efectivo y real sobre los aspectos de la reglamentación contractual.

2. A través de la prohibición de cláusulas abusivas.

3. Mediante el control previo sobre las condiciones generales antes y al margen de haberse celebrado el contrato ${ }^{163}$.

La legislación nicaragüense vigente ofrece un cierto control sobre las condiciones generales en los contratos de adhesión, tanto en cuanto a su incorporación como en su contenido.

162 NAVAS MENDOZA Azucena, Curso Básico de Derecho Mercantil, Tomo II, León, Nicaragua, Editorial Universitaria, UNAN, León, 2004, página 184.

163 HERRERA Jesús, GUZMÁN Jairo; Contratos Civiles y Mercantiles; $1^{\text {a }}$ Edición, Managua, Nicaragua, Universidad Centroamericana, Mayo 2006; página 167. 


\section{Revista de ODerecho}

El "control de incorporación" se refiere a los requisitos que debe cumplir en cuanto a la forma, cuya finalidad es evitar que las condiciones generales sean de total desconocimiento por el usuario, garantizando, por consiguiente, que dichas cláusulas hayan sido aceptadas en cada particular negocio ${ }^{164}$.

El "control del contenido" de las condiciones generales de la contratación, se refiere a la sustancia del contrato, siendo su finalidad pretender evitar, en razón de la buena fe contractual, la eficacia de aquellas "cláusulas abusivas", es decir, las que causen lesión desproporcionada al otro contratante ${ }^{165}$.

En este sentido tanto el artículo 10 de la Ley 515, como el artículo 6 de la Norma sobre la Promoción y Ordenamiento de la Tarjeta de Crédito, establecen una serie de condiciones mínimas que debe reunir el contrato de emisión de la tarjeta de crédito, abordadas previamente en el presente trabajo.

\section{Definición}

La determinación de lo que debe entenderse por cláusula abusiva en el contrato es uno de los problemas que tiene actualmente planteado el Derecho europeo, y cuyas soluciones no son por el momento uniformes. En lo que concierne a la legislación nicaragüense en materia de tarjetas de crédito y de defensa del consumidor, éstas no han aportado una noción general ni una definición exacta y objetiva de lo qué debe entenderse por "cláusula abusiva”, definición que de existir, permitiría ampliar el alcance del listado o catálogo enumerativo, no exhaustivo, de cláusulas en todo caso prohibitivas, elaboradas por el legislador en materia de defensa de los consumidores y emisión y uso de la tarjeta de crédito, y que de aparecer en el contrato se tendrán por no puestas y se les sanciona con nulidad.

A pesar de no existir una noción de tal tenor, la misma deberá incluir al menos tres elementos claves que permitan configurarla:

164 HERRERA Jesús, GUZMÁN Jairo; Contratos Civiles y Mercantiles; $1{ }^{a}$ Edición, Managua, Nicaragua, Universidad Centroamericana, Mayo 2006; página 167.

165 HERRERA Jesús, GUZMÁN Jairo; Contratos Civiles y Mercantiles; $1^{\text {a }}$ Edición, Managua, Nicaragua, Universidad Centroamericana, Mayo 2006; página 170. 


\section{Revisla de Derecho}

1. Ha de tratarse de cláusulas no negociadas individualmente.

2. Deben ser contrarias a las exigencias de la buena fe.

3. Deben causar un perjuicio al consumidor, es decir producir una ruptura al principio de equivalencia de las prestaciones, un desequilibrio importante entre los derechos y obligaciones que se derivan del contrato ${ }^{166}$.

Por lo antes expuesto y partiendo de dichos puntos, en concreto, la cláusula abusiva podría definirse de la siguiente manera:

Cláusula abusiva es aquélla que se incluye en los contratos y es contraria a la buena fe y al justo equilibrio entre los derechos y obligaciones de las partes (consumidor y profesional), en perjuicio del consumidor, y que no ha sido negociada individualmente entre las dos partes.

En España, la Ley de Condiciones Generales de Contratación prescribe en su artículo 10 una definición más o menos completa sobre las cláusulas abusivas en los contratos celebrados con los consumidores, ésta es:

"Son cláusulas contractuales abusivas las que no se hayan negociado individualmente si, pese a las exigencias de la buena fe, causan en detrimento al consumidor un desequilibrio importante entre los derechos y obligaciones de las partes que se derivan del contrato".

En el mismo sentido, el artículo 9 de la AGB-Gesetz alemana, contiene una cláusula general de prohibición e ineficacia de cláusulas abusivas al tenor de la cual, se consideran abusivas aquellas cláusulas que "producen un perjuicio de manera desproporcionada al consumidor en contra de la buena fe y la equidad".

2. Catálogo de cláusulas abusivas establecidas en nuestro ordenamiento $y$ en el derecho comparado

El artículo 11 de la Ley 515 establece que en el contrato de apertura en cuenta corriente y emisión y uso de la tarjeta de crédito, "serán nulas" las siguientes cláusulas:

1. Las que importen la renuncia por parte del titular a cualquiera de los derechos y garantías que otorga la Ley 515

166 Artículo 8. Norma sobre la Promoción y Ordenamiento del Uso de la Tarjeta de Crédito. 
2. Las que faculten al emisor a modificar unilateralmente las condiciones del contrato

El contrato de emisión de tarjeta de crédito deberá cumplir con las condiciones establecidas en el artículo 10 de la Ley 515, y en el artículo 6 de la Norma sobre la Promoción y Ordenamiento del Uso de la Tarjeta de Crédito, y para cualquier modificación o adición del contrato el emisor deberá contar con la aprobación del ente regulador (Superintendente).

3. Las que impongan un monto fijo por atrasos en el pago de su adeudo. Los intereses corrientes o moratorios, en su caso, sólo se cobrarán sobre saldos deudores. Los intereses moratorios no son capitalizables. Esto significa que en ningún caso se podrá cobrar interés sobre interés

Así mismo, lo antes expuesto se complementa con lo establecido en el artículo 4 de la Ley 515, al señalar que los intereses moratorios no podrán exceder en monto ni cuantía a la deuda principal, y cuando se reclamare la deuda principal y los intereses moratorios, estos últimos no podrán exceder el 25\% del adeudo principal.

4. Las que impongan costos por informar la no validez de la tarjeta, sea por pérdida, sustracción, caducidad o rescisión contractual

En caso de pérdida, extravío o destrucción de la tarjeta de crédito el emisor de la misma deberá poner a disposición del usuario un número telefónico con servicio las veinticuatro horas del día (gratuito) con el único fin de recibir informe sobre robo, extravío o pérdida de la tarjeta de crédito para su bloqueo de forma inmediata por parte del emisor.

5. Las cláusulas adicionales no autorizadas por el órgano regulador

$\mathrm{Al}$ respecto, el artículo 7 de la Norma sobre la Promoción y Ordenamiento del Uso de la Tarjeta de Crédito señala que cuando los emisores de la tarjeta de crédito requieran agregar nuevas cláusulas al contrato que la emite o reformar las existentes, deberán de previo solicitar la autorización del Superintendente (órgano regulador), y una vez aprobadas deberán ser publicadas por el emisor en cualquier medio de comunicación social escrito de circulación nacional. A esto suele denominársele como "control de incorporación”, pretendiendo evitar de esta manera que las 


\section{Revista de Derecho}

condiciones generales que comprendan el contrato, sean desconocidas por el usuario, y por consiguiente, garantizar que éstas no sólo sean autorizadas de previo, sino que sean aceptadas en cada particular negocio.

6. Las que autoricen al emisor la rescisión unilateral del contrato sin causa previamente acordada en el mismo

El emisor, únicamente, podrá poner fin al contrato de manera unilateral cuando hubiere causa justificada, notificando de ello al tarjetahabiente por cualquier medio escrito. En tal caso, el emisor podrá suspender el uso de la línea de crédito y el tarjetahabiente continuará con su responsabilidad por los saldos no cubiertos, la tasa de interés y las demás condiciones contenidas en el contrato ${ }^{167}$.

7. Las que impongan compulsivamente al titular un representante

El titular o tarjeta habiente, previamente identificado con cédula de identidad, actúa en su carácter personal (persona natural) o en representación de alguna persona jurídica, conviniendo la celebración del contrato, aceptando las condiciones en él expresadas y firmando.

8. Las que le impongan al usuario de la tarjeta, un domicilio diferente al propio

En el contrato de apertura de crédito en cuenta corriente y de emisión y uso de la tarjeta de crédito, el tarjetahabiente deberá señalar su domicilio, lugar habitual de residencia y el que usa en todos sus contratos y negocios, para todos los efectos procesales y legales.

Además de las nulidades establecidas en la Ley 515, la Ley de Defensa de los Consumidores y su Reglamento se encuentran también, de forma adicional, algunas cláusulas que siendo incorporadas en el contrato se considerarían nulas, tales son:

1. Exoneración del proveedor de su responsabilidad civil, salvo que el consumidor caiga en incumplimiento del contrato ${ }^{168}$.

167 Artículo 24, inciso b) de la Ley de Defensa de los Consumidores.

168 Artículo 24, inciso c) de la Ley de Defensa de los Consumidores. 


\section{Revista de ODerecho}

2. Fijación de términos de prescripción inferiores a los establecidos en el Código Civil ${ }^{169}$.

3. Limitar u obstaculizar el derecho de acción del consumidor contra el proveedor, o invertir la carga de la prueba en perjuicio del consumidor ${ }^{170}$.

4. Imposición obligatoria del arbitraje $\mathrm{e}^{171}$.

Las cláusulas anteriormente señaladas son aplicables de forma supletoria y a su vez complementaria a las ya establecidas en el artículo 11 de la Ley 515 , fundamentada en el hecho de que usuarios de la tarjeta adquieren un crédito con el objetivo de adquirir o utilizar como destinatarios finales, bienes, productos o servicios de cualquier naturaleza.

Sin embargo, considero se hace necesario realizar un pequeño estudio comparativo con otras legislaciones latinoamericanas, de manera que se pueda obtener una visión más amplia de la regulación implementada en relación a las cláusulas abusivas en los contratos mediante los cuales se emiten las tarjetas de crédito.

Es así que a partir del cuadro subsiguiente, procederé a analizar comparativamente la Ley 515, Ley de Promoción y Ordenamiento del Uso de la Tarjeta de Crédito, con la Ley de Tarjeta de Crédito hondureña y la argentina, de manera que se pueda visualizar mediante un cuadro, qué cláusulas que nuestra norma considera abusivas no están incorporadas en otras legislaciones, y a su vez las cláusulas que contienen las otras legislaciones (hondureña y argentina) que nuestro sistema no recoge pero que se consideraría adecuada su incorporación, en busca de una protección más efectiva del usuario de la tarjeta de crédito.

169 Artículo 24, inciso d) de la Ley de Defensa de los Consumidores.

170 Artículo 24, inciso e) de la Ley de Defensa de los Consumidores.

171 ESCOBAR FORNOS, Iván; Derecho de Obligaciones; 2da. Edición, Managua; HISPAMER 2000; página 505 . 
Revista de Derecho

\begin{tabular}{|c|c|c|}
\hline $\begin{array}{l}\text { Art. } 11 \text { Ley } 515 . \\
\text { (Nicaragua) }\end{array}$ & $\begin{array}{l}\text { Art. 31 Ley de Tarjetas } \\
\text { de Crédito (Honduras) }\end{array}$ & $\begin{array}{l}\text { Art. 14 de la } \\
\text { Tarjetas de de } \\
\text { (Argentina) }\end{array}$ \\
\hline $\begin{array}{l}\text { 1. Las que importen la } \\
\text { renuncia a cualquiera de } \\
\text { los derechos y garantías } \\
\text { que otorga la presente ley. }\end{array}$ & & $\begin{array}{l}\text { Las que importen una } \\
\text { renuncia por parte del } \\
\text { titular a cualquiera de los } \\
\text { derechos que otorga la } \\
\text { presente ley. }\end{array}$ \\
\hline & $\begin{array}{l}\text { Las que modifiquen o } \\
\text { declaren en suspenso } \\
\text { condiciones establecidas } \\
\text { en la presente ley y demás } \\
\text { normativas aplicables. }\end{array}$ & \\
\hline $\begin{array}{l}\text { 2. Las que faculten al } \\
\text { emisor a modificar } \\
\text { unilateralmente r las } \\
\text { condiciones del contrato. }\end{array}$ & $\begin{array}{l}\text { Las que faculten al emisor } \\
\text { a modificar las } \\
\text { condiciones de los } \\
\text { contratos, estableciendo } \\
\text { cargos adicionales no } \\
\text { pactados con el tarjeta } \\
\text { habiente, salvo que } \\
\text { correspondan a beneficios } \\
\text { adicionales susceptibles } \\
\text { de ser aceptados o } \\
\text { rechazados por escrito, o } \\
\text { por otros medios tales } \\
\text { como: correos } \\
\text { electrónicos. }\end{array}$ & $\begin{array}{l}\text { Las que faculten al emisor } \\
\text { a modificar } \\
\text { unilateralmenter las } \\
\text { condiciones del contrato. }\end{array}$ \\
\hline $\begin{array}{l}\text { 3. Las que impongan un } \\
\text { monto fijo por atrasos en el } \\
\text { pago de lo adeudado. Los } \\
\text { intereses corrientes o } \\
\text { moratorios en su caso, sólo } \\
\text { se cobrarán sobre saldos } \\
\text { deudores. Los intereses } \\
\text { moratorios no son } \\
\text { capitalizables. } \\
\text { significa que en ningún } \\
\text { caso se podrá cobrar interés } \\
\text { sobre interés. }\end{array}$ & & $\begin{array}{l}\text { Las que impongan un } \\
\text { monto fijo por atrasos en el } \\
\text { pago del resumen. }\end{array}$ \\
\hline
\end{tabular}




\begin{tabular}{|c|c|c|}
\hline $\begin{array}{l}\text { 4. Las que impongan } \\
\text { costos por informar la no } \\
\text { validez de la tarjeta, sea } \\
\text { por pérdida, sustracción, } \\
\text { caducidad o rescisión } \\
\text { contractual. }\end{array}$ & $\begin{array}{l}\text { Las que impongan costos } \\
\text { por informar la no validez } \\
\text { de la no validez de la } \\
\text { tarjeta, sea por pérdida, } \\
\text { sustracción, caducidad o } \\
\text { terminación del contrato. }\end{array}$ & $\begin{array}{l}\text { Las que impongan costos } \\
\text { por informar la no validez } \\
\text { de la tarjeta, sea por } \\
\text { pérdida, sustracción, } \\
\text { caducidad o rescisión } \\
\text { contractual. }\end{array}$ \\
\hline \multirow[t]{4}{*}{$\begin{array}{l}\text { 5. Las cláusulas adicionales } \\
\text { no autorizadas por el } \\
\text { órgano regulador }\end{array}$} & $\begin{array}{l}\text { Las cláusulas adicionales } \\
\text { no autorizadas, agregadas } \\
\text { al modelo de contrato } \\
\text { aprobado por la } \\
\text { comisión. }\end{array}$ & \\
\hline & & $\begin{array}{l}\text { Las adhesiones tácitas a } \\
\text { sistemas anexos al sistema } \\
\text { de tarjeta de crédito. }\end{array}$ \\
\hline & $\begin{array}{l}\text { Las que contengan } \\
\text { espacios en blanco }\end{array}$ & \\
\hline & $\begin{array}{l}\text { Las redactadas en idioma } \\
\text { distinto al español, o con } \\
\text { caracteres ilegibles } \\
\text { utilizando una letra } \\
\text { inferior de tamaño } \\
\text { número 12. }\end{array}$ & \\
\hline $\begin{array}{l}\text { 6. Las que impongan } \\
\text { compulsivamente al titular } \\
\text { un representante. }\end{array}$ & & $\begin{array}{l}\text { Las que impongan } \\
\text { compulsivamente al titular } \\
\text { un representante. }\end{array}$ \\
\hline \multirow{3}{*}{$\begin{array}{l}\text { 7. Las que autoricen al } \\
\text { emisor la rescisión } \\
\text { unilateral del contrato sin } \\
\text { causa } \\
\text { acordada en el mismo. } \\
\text { 8. Las que impongan al } \\
\text { usuario de la tarjeta, un } \\
\text { domicilio diferente al } \\
\text { propio. }\end{array}$} & & \\
\hline & & \\
\hline & $\begin{array}{l}\text { Las que exijan al tarjeta- } \\
\text { habiente, la suscripción de } \\
\text { títulos valores en blanco } \\
\text { para exigir el pago de } \\
\text { saldos insolutos. } \\
\text { Cualquier otra cláusula } \\
\text { contraria a lo dispuesto e la } \\
\text { presente ley o en el resto de } \\
\text { la legislación aplicable. }\end{array}$ & \\
\hline
\end{tabular}




\section{Revista de Derecho}

Primeramente, es de aclararse que en ninguna de estas normas, incluyendola nuestra, se hace mención de "cláusulas abusivas" comotales, ni se establece una definición de las mismas, limitándose únicamente, a realizar una enumeración taxativa de una serie de cláusulas que de ser incorporadas en los contratos de emisión de tarjetas de crédito, se considerarían nulas.

Ahora bien, partiendo del cuadro anterior y con auxilio de las otras legislaciones, además de las cláusulas que de hecho se consideran nulas a la luz de la Ley 515, sería importante y necesario incorporar al catálogo formulado por el legislador nicaragüense, las siguientes:

1. Las que modifiquen o declaren en suspenso condiciones establecidas en la presente ley y demás normativas aplicables.

2. Las que contengan espacios en blanco.

3. Las redactadas en idioma distinto al español, o con caracteres ilegibles utilizando una letra inferior de tamaño número 12.

Tanto la Ley 515, como la Norma sobre la Promoción y Ordenamiento del uso de la Tarjeta de Crédito, hacen referencia a esto, únicamente sólo para efectos de las condiciones que el contrato debe reunir.

En dichas normas no se exige que la redacción del contrato deba realizarse en el idioma español y en cuanto al tamaño de la letra no se especifica tamaño exacto, estableciéndose simplemente que no podrá ser menor al tamaño y tipo de letra utilizados para las publicaciones en el Diario Oficial, La Gaceta, hecho que no es de conocimiento general.

4. Las que exijan al tarjetahabiente, la suscripción de títulos valores en blanco para exigir el pago de saldos insolutos.

5. Cualquier otra cláusula contraria a lo dispuesto en la presente ley o en el resto de la legislación aplicable.

3. Cláusulas abusivas más usualmente utilizadas en los contratos de emisión de la tarjeta de crédito

Luego de haber realizado una revisión de dos contratos de apertura de crédito en cuenta corriente y emisión y uso de la tarjeta de crédito, elaborados unilateralmente por dos instituciones bancarias distintas que operan en nuestro país, y de los cuales omitiré nombre, he logrado 
constatar que cumplen casi en su totalidad en la no incorporación de cláusulas que para efecto de la Ley 515 se consideran nulas; sin embargo me atrevo a realizar las siguientes observaciones:

- De inicio el contrato en mención es un formato previamente elaborado con espacios en blanco que deben ser llenados en presencia del acreditado o tarjetahabiente. Entre esos espacios en blancos se encuentra el límite original de crédito que tiene la tarjeta de crédito, monto que es aceptado prácticamente por el tarjetahabiente al momento de la firma del contrato, pero el emisor en una de las cláusulas aparece facultado para variar cualquier monto o límite de crédito, sin embargo en ningún momento se dice que para ello se necesita de la autorización o anuencia del usuario de dicha tarjeta. $\mathrm{He}$ ahí un abuso por la modificación unilateral de una de las condiciones del contrato.

- Por otro lado, se garantiza al tarjetahabiente el estado de cuenta en la dirección que este señale con la información requerida por la ley, pero literalmente en la misma cláusula en que se aborda dicha obligación, se establece: "El atraso o falta de recibo de los estados de cuenta no justifica que el tarjetahabiente deje de efectuar los pagos a que está obligado en la fecha que le corresponda, según lo pactado”. Ello significa que el banco se está eximiendo de responsabilidad en la entrega retrazada de dicho estado de cuenta y que los intereses moratorios seguirán corriendo aun con dicha omisión. Si bien es cierto que esto no corresponde a ninguna de las clausules sancionadas con nulidad en la ley, pero considero que implica una infracción a un derecho establecido a favor del tarjetahabiente.

- Otra de las condiciones que en general pactan los bancos en los contratos, es aquella que prevé cómo acreditante o emisor pueden poner fin al contrato "de manera unilateral cuando hubiere causa justificada contemplada en la cláusula correspondiente”. Sin embargo, dicha facultad concedida al emisor no está fundamentada, por la falta de una enumeración en el contrato mismo de las causas por las cuales el emisor puede rescindir de manera unilateral el contrato. Ello constituye una cláusula abusiva contemplada en el inciso 6 del artículo 11 de la Ley 515.

\section{Mecanismos de defensa frente a las cláusulas abusivas}

Ante la posible existencia de cláusulas abusivas en los contratos de emisión de tarjetas de crédito, es preciso preguntarse ¿qué mecanismos de protección o defensa le otorga la ley al usuario o tarjetahabiente? ¿En qué ley se fundamentaría? ¿Qué vía procesal debería utilizarse? 


\section{Revista de ODerecho}

Para iniciar, la Ley 515, de Promoción y Ordenamiento del Uso de la Tarjeta de Crédito, únicamente establece, en su artículo 11, un catálogo de cláusulas que de incorporarse en el contrato son sancionables con su nulidad; sin embargo dicha norma no ofrece ningún mecanismo que pueda utilizar el usuario de la tarjeta para impugnar la o las cláusulas abusivas integradas en el contrato y que además le produzca algún perjuicio; en consecuencia, tampoco se encuentra procedimiento mediante el cual pueda dirimirse el asunto.

El único procedimiento del que se habla en materia de tarjetas de crédito, no así de cláusulas abusivas, es el de impugnación del estado de cuenta, consignado en el artículo 17 y siguientes, de la Norma sobre la Promoción y Ordenamiento del Uso de la Tarjeta de Crédito, ya abordado someramente con anterioridad en el presente trabajo.

Tampoco puede recurrirse ante la Superintendecia de Bancos y Otras Instituciones Financieras debido a que no se encuentra expresamente dentro de sus atribuciones, mismas que se encuentran señaladas en el artículo 3 de Ley 316, Ley de la Superintendecia de Bancos y Otras Instituciones Financieras, y que están orientadas a la fiscalización, vigilancia y control "general" de las instituciones bancarias y las operaciones que estos realicen, pero no se confiere una facultad expresa en la materia que nos ocupa, lo que ha llevado a que la SIBOIF rehuya a este tipo de labor.

Con todo, en materia de tarjetas de crédito, fundamentado en el interés público, la Superintendencia como órgano regulador es quien aprueba los modelos de contratos de apertura de crédito en cuenta corriente y emisión y uso de la tarjeta de crédito que serán utilizados, de conformidad con el artículo 5 de la Ley 515.

Por otro lado, nos encontramos ante la existencia de la Ley de Defensa de los Consumidores y su Reglamento, cuyo órgano de aplicación es la Dirección de Defensa de los Consumidores.

En el artículo 14 del Reglamento de dicha Ley, se encuentra señalado un procedimiento específico ante cualquier infracción a la misma, iniciado a través de una demanda, cuya competencia ostenta la Dirección de Defensa de los Consumidores (DDC). Sin embargo, aunque de alguna manera la Ley de Defensa del Consumidor (Ley 182) suple muchos 


\section{Revista de ODerecho}

de los vacíos encontrados en la Ley 515, en nuestro foro se considera que el usuario de la tarjeta de crédito no puede recurrir ante el órgano mencionado anteriormente, denunciando o demandando la nulidad de alguna o algunas de las cláusulas abusivas impuestas en el contrato, debido a que la DDC considera que el ámbito de aplicación de la Ley 182 está dirigido únicamente a garantizar la adquisición general de bienes y servicios, y no de forma específica a los servicios bancarios, ya que se entiende que tales servicios deben de ser tutelados por la SIBOIF, cuestión que como ya vimos no es del todo cierta.

Finalmente, siendo que el contrato de emisión de tarjeta de crédito se encuentra también regido por el Código Civil, es importante revisar la opción de que el usuario pueda atacar las cláusulas abusivas por la vía judicial, y más específicamente la civil, ejerciendo acción de nulidad.

La nulidad es un vicio o defecto de fondo o de forma, que deja sin valor o eficacia a un acto o contrato ${ }^{172}$. La Ley señala ciertos requisitos y formalidades para la celebración de dichos actos jurídicos, con la finalidad de rodearlos de garantías que aseguren su seriedad. No cumpliéndose dichos requisitos, la misma ley sanciona el acto o contrato con su nulidad. Por lo tanto, en su aspecto civil, la nulidad es la sanción inherente a todo acto jurídico celebrado sin observar las reglas establecidas por la ley, para asegurar la defensa del interés general, o para expresar la protección de un interés privado ${ }^{173}$. Ahora bien, desde el punto de vista de la extensión en que la nulidad afecte el acto, esta puede ser total o parcial. Es total cuando afecta a todo el acto. Es parcial cuando sólo afecta una parte del mismo, es decir, que una cláusula no afecta a las demás, siempre que sean separables.

En vista de lo antes expuesto, en mi opinión, el usuario de la tarjeta de crédito que se considere afectado por la imposición de cláusulas abusivas, conforme a la ley, en el contrato de emisión de la tarjeta de crédito, puede perfectamente demandar al emisor, ejerciendo a tal efecto, la acción de nulidad parcial del contrato, es decir, sobre la o las cláusulas que lo afecten, con fundamento en los artículos 2205 y 2217 C.

172 MARQUEZ GONZALEZ, José Antonio, Teoría General de las Nulidades, Editorial Porrúa, 2da. Edición, México DF 1996, página 83.

173 Diccionario Jurídico ESPASA; Edición Espasa Calpe S.A, Madrid 2005, página 1170. 
El tema de los privilegios bancarios es un tema bastante amplio y para lo cual se haría necesario un estudio individual mediante el cual pueda analizarse uno a uno, lo cual, obviamente, no es objeto del presente trabajo.

Ahora bien, para entender un poco el significado de privilegio bancario, es necesario comprender que un privilegio es un acto administrativo singular por el que se concede una gracia a una persona determinada (física o jurídica); reviste la forma de rescripto y su contenido dispositivo graciable consiste, ordinariamente, en que su destinatario deje de cumplir algo a lo que viene urgido por la ley o pueda hacer algo prohibido por la misma ${ }^{174}$.

Por lo tanto, los privilegios bancarios son precisamente normas de excepción establecidas a favor de los bancos y otras instituciones financieras, en el artículo 59 de la Ley 561, Ley General de Bancos, Instituciones Financieras No Bancarias y Grupos Financieros. Dichos privilegios están orientados a que dichas instituciones logren recuperar el crédito otorgado a sus clientes, de modo que están referidos a la mora, a la solidaridad de los deudores y fiadores, a la fianza, la prenda (comerciar/industrial), los requerimientos de pago, entre otros asuntos. En materia de tarjeta de crédito, estos privilegios de que se habla, no son sinónimo de impunibilidad para los bancos como emisores de tarjetas de crédito, sino más bien un medio para garantizarse el crédito.

\section{Valoración general del sistema de protección frente a las cláusulas abusivas}

De inicio, conviene poner en evidencia que es harto difícil valorar el sistema de protección aludido debido a que no existe siquiera un mecanismo de defensa, establecido en la Ley 515, que pueda invocar el

174 Ley No. 380, Ley de Marcas y Otros Signos Distintivos, publicada en La Gaceta, Diario Oficial No. 70 del 16 de abril del 2001. “Art. 8. Marcas Inadmisibles por Derechos de Terceros. No podrá ser registrado como marca un signo cuyo uso afectaría un derecho anterior de tercero. Se entiende afectado un derecho anterior de tercero, entre otros, en cualquiera de los siguientes casos ... b) El signo es idéntico o similar a una marca registrada o en trámite de registro en el país por un tercero desde una fecha anterior, que distingue los mismos o diferentes productos o servicios, si su uso pudiera causar un riesgo de confusión o de asociación con esa marca." 


\section{Revista de ODerecho}

usuario o tarjetahabiente ante la imposición de cláusulas abusivas en el contrato al que se adhiere.

En el tema de las cláusulas abusivas existen muchos vacíos en la Ley 515: como hacía mención con anterioridad, no existe siquiera una definición de lo qué debería entenderse como cláusulas abusivas; tampoco se establece en el artículo 11 de la ley que dichas cláusulas son nulas porque las mismas son consideradas un abuso para el usuario, ni mucho menos mediante qué medio podrían denunciarse o atacarse y bajo qué procedimiento podría dirimirse esa situación. Es así que puede visualizarse que la Ley 515 deja en franca desprotección e indefensión al usuario en el caso de que el emisor haya impreso en sus contratos cláusulas abusivas, contrarias a la Ley.

Sin embargo, como el usuario de la tarjeta de crédito debe defender de alguna manera su derecho ante tal abuso, el Código Civil, de forma supletoria, muestra una alternativa viable, la vía judicial ordinaria, ejerciendo la acción de nulidad del contrato, siguiendo la línea de los contratos civiles. Pero esta no es la mejor vía ni el procedimiento para que los usuarios puedan hacer su denuncia o protesta, debido a que el contrato de emisión de tarjeta de crédito es un contrato estrictamente bancario, con sus particularidades específicas, haciéndose urgente que se le proporcione al tarjeta habiente la vía, medio o mecanismo para hacer efectivo su derecho.

\section{Conclusiones}

1. El contrato de emisión de tarjeta de crédito tiene generalmente la forma de una solicitud o formularios preimpresos con cláusulas generales impuestas por la empresa emisora, solicitud que por lo general muchos usuarios no leen por ser tan extensos, escritos en un tamaño de letra bastante pequeña y con el empleo de lenguaje técnicolegal, de manera que dificulta su comprensión por parte del usuario o consumidor. En consecuencia, ante tal circunstancia, dichos usuarios corren el riesgo de ser engañados, dañados y abusados por el emisor, firmando el contrato casi a ciegas debido a la falta de conocimiento absoluto del mismo. Con todo, actualmente muchas empresas emisoras usualmente otorgan tarjetas aprobadas previamente, sin necesidad de la solicitud, bastando que el titular acepte la tarjeta de crédito, la firme y avise al emisor que la ha recibido. 


\section{Revista de Derecho}

2. En lo que concierne a la legislación nicaragüense en materia de tarjetas de crédito y de defensa del consumidor, ésta no ha aportado una noción general ni una definición exacta y objetiva de lo qué debe entenderse por "cláusula abusiva", definición que de existir, permitiría ampliar el alcance del listado o catálogo enumerativo, no exhaustivo, de cláusulas en todo caso prohibitivas, elaboradas por el legislador en materia de defensa de los consumidores y emisión y uso de la tarjeta de crédito, y que de aparecer en el contrato, se tendrán por no puestas y se les sanciona con nulidad.

3. La Ley 515 no ofrece ningún mecanismo que pueda utilizar el usuario de la tarjeta para impugnar la o las cláusulas abusivas integradas en el contrato, y que además le produzcan algún perjuicio; en consecuencia, tampoco se encuentra un procedimiento mediante el cual pueda dirimirse el asunto. La única alternativa que tiene el usuario para defenderse ante la existencia de cláusulas abusivas es la vía judicial ordinaria, ejerciendo la acción de nulidad.

4. Las cláusulas que se establecen como nulas en la Ley 515 no son suficientes, no otorgan una protección completa al usuario en tanto que presentan vacíos, inconsistencias y contradicciones.

\section{Recomendaciones}

1. Se hace necesaria la implementación de un formato de solicitud de tarjeta de crédito y adicionalmente un formato que constituya en su contenido el contrato de emisión de tarjeta de crédito.

2. En cuanto a los contratos de emisión de tarjeta de crédito, el órgano de control debe garantizar efectivamente que:

- Sean escritos con letra legible de manera que puedan apreciarse por una persona de visión normal.

- Sean redactados en términos de fácil comprensión para el usuario.

- Exista claridad en cuanto al procedimiento de cálculo de intereses.

- Los espacios en blanco sean llenados en presencia del usuario o tarjetahabiente.

- No contengan cláusulas abusivas.

3. Debe educarse al usuario no sólo para el uso de la tarjeta de crédito sino también para la comprensión de la metodología de cálculo que utiliza el emisor para el cobro de intereses y comisiones que se verán materializadas en el estado de cuenta correspondiente.

4. Es urgente una reforma a la Ley 515 en los siguientes sentidos: 
- Que ésta aporte una noción general de lo que debe entenderse como cláusulas abusivas.

- Ampliar el catálogo enumerativo de las cláusulas que de incorporarse en el contrato de emisión de tarjetas de crédito, se consideran nulas por ser abusivas.

- Incorporar mecanismos de defensa en la vía administrativa, para que el usuario o tarjetahabiente pueda utilizarlos ante la afectación por la imposición de cláusulas abusivas en los contratos.

- Crear una institución o dirección encargada de proteger y resguardar debidamente los derechos de los usuarios o tarjetahabientes.

\section{Bibliografía}

\section{Textos}

BARBIERI, Pablo C., "Contratos de financiación: tarjeta de crédito" en: contratos de empresa; edicitorial Universidad; 1998.

BENDAÑA GUERRERO, Guy; “Tarjeta de crédito”, en Estudio de los contratos, $1^{\text {a }}$ edición; Managua; 2001.

Diccionario Jurídico ESPASA; Edición Espasa Calpe S.A, Madrid 2005.

ESCOBAR FORNOS, Iván; Derecho de obligaciones, $2^{\mathrm{a}}$ edic.; Managua; Hispamer; 2000.

GÓMEZ PORRÚA, Juan Manuel; "La tarjeta de crédito" en, Derecho Mercantil, vol. II, $4^{\text {a }}$ edición, dirigido por Guillermo Jiménez Sánchez; Ariel; Barcelona; 1997.

HERRERA ESPINOZA, Jesús Jusseth; Derecho Bancario doctrina y legislación, $2^{\text {a }}$ edic.; UCA; Managua; 2008.

HERRERA ESPINOZA, Jesús Jusseth/GUZMÁN GARCÍA, Jairo José; Contratos Civiles y Mercantiles, $1^{\text {a }}$ edic. UCA, Managua, 2006.

MOJICA, Luis/O’MIER, Francis/TÉLLEZ, Orlandina; La tarjeta de crédito y su regulación en Nicaragua; monografía (Licenciatura en Derecho) UNAN-LEÓN. 


\section{Revisla de Derecho}

MONTERREY RÍOS, Lydia; El contrato bancario de tarjeta de crédito en la legislación española y nicaragüense y el proyecto de ley que lo regula. Tercer trimestre 2002 (Maestría en Derecho Privado); León; Universidad Nacional Autónoma de Nicaragua.

NAVAS MENDOZA, Azucena; Curso básico de Derecho Mercantil, tomo II; Editorial universitaria; León; 2004.

\section{Legislación}

Decreto de la Asamblea Nacional $\mathrm{N}^{\circ}$ 2187, Reglamento a la Ley $\mathrm{N}^{\circ} 182$, publicado en La Gaceta, Diario Oficial No 169 del 3 de septiembre de 1999.

Ley $\mathrm{N}^{\circ} 182$, Ley de Defensa de los Consumidores, publicada en La Gaceta, Diario Oficial No 213 del 14 de noviembre de 1994.

Ley $\mathrm{N}^{0}$ 561, Ley General de Bancos, Instituciones Financieras no Bancarias y Grupos Financieros publicada en La Gaceta, Diario Oficial $\mathrm{N}^{0} 232$ del 20 de noviembre de 2005.

Ley No 515, Ley de Promoción y Ordenamiento del Uso de la Tarjeta de Crédito publicada en La Gaceta, Diario Oficial $\mathrm{N}^{\circ} 11$ del 17 de enero de 2005.

Ley $\mathrm{N}^{\circ} 316$, Ley de la Superintendencia de Bancos y de Otras Instituciones Financieras publicada en La Gaceta, Diario Oficial No 196 del 14 de octubre de 1999.

Resolución No CD-SIBOIF-443-1-SEP26-2006, Norma sobre la Promoción y Ordenamiento del Uso de la Tarjeta de Crédito; publicada en La Gaceta, Diario Oficial No 198 del 12 de octubre de 2006.

\section{Consultas en línea}

Declaración Universal de Derechos de los Usuarios de Servicios Bancarios y Financieros. Salamanca, 29 y 30 de septiembre de 2005 (consultado el 30 de octubre de 2008) disponible en la dirección: www.consumidoreslibres.org/declaración_esp.pdf. 